ARTICLE

\title{
Care requirements of patients with advanced cancer within a specialist centre - moving to person-centered approaches
}

\author{
Donna Milne RN PhD ${ }^{a}$ Lisa Sheeran RN BN ${ }^{b}$ Tracey Dryden RN BN MSc ${ }^{c}$ Linda Mileshkin \\ MBBS MBioeth MD ${ }^{\mathrm{d}}$ and Sanchia Aranda RN PhD
}

\author{
a Senior Clinician Researcher, Department of Nursing and Supportive Care Research, Peter McCallum Cancer \\ Centre, East Melbourne, Victoria, Australia \\ b Clinician Researcher, Department of Nursing and Supportive Care Research, Peter McCallum Cancer Centre, \\ East Melbourne, Victoria, Australia \\ c Clinician Researcher, Department of Nursing and Supportive Care Research, Peter McCallum Cancer Centre, \\ East Melbourne, Victoria, Australia \\ d Consultant in Medical Oncology, Department of Nursing and Supportive Care Research, Peter McCallum \\ Cancer Centre, East Melbourne, Victoria, Australia \\ e Professor and Director of Cancer Nursing Research, Department of Nursing and Supportive Care Research, \\ Peter McCallum Cancer Centre, East Melbourne, Victoria, Australia
}

\begin{abstract}
Despite the prolonged survival of many patients with advanced cancer and the increasing conceptualization of cancer as a chronic illness, care delivery systems within the Australian context continue to manage advanced cancer as an acute illness. Patients living with advanced cancer are managed alongside those with curable cancers in ambulatory models of care that centre on diagnosis, treatment decision-making or post treatment surveillance. Conversely, the needs of people with advanced disease are often complex, requiring high levels of collaboration between providers across acute, palliative and primary care settings in order to move forwards to a more person-centered approach to care.

Aims:

This paper addresses three specific aims:

1. to identify the care requirements and concerns of patients and their carers;

2. to examine the role of out-reach telephone calls as a component of care;

3. to identify the nurse's role in care coordination for patients with advanced cancer.

Method:

Two nurse clinician researchers (CR) managed a cohort of patients with advanced breast $(n=12)$ and gastrointestinal cancers $(n=16)$ over six and nine months respectively. Data were recorded on every interaction between the CRs and the patients, carers and other health professionals. The CRs were interviewed by an independent nurse researcher.

Results:

The symptoms and issues causing concern to patients and/or carers included pain, weakness, gastrointestinal symptoms, managing appointments and dealing with anxiety. The CR played a major role in coordinating care to address these concerns and found out-reach telephone calls facilitated the process.

Conclusions:

Patients with advanced cancer have complex needs and care coordination requirements not routinely met in an acute care setting. Input from a nurse working at an advanced level and the use of out-reach telephone calls can assist in meeting these care needs.
\end{abstract}

\section{Keywords}

Advanced cancer, care requirements, patient needs, outreach phone calls

\section{Correspondence Address}

Dr Donna Milne, Department of Nursing and Supportive Care Research, Peter MacCallum Cancer Centre Locked Bag 1, A’Beckett Street, Victoria 8006, Australia. E-mail : Donna.Milne@petermac.org

Accepted for publication: 31 January 2011 


\section{Introduction}

People with cancer are living longer with around 60\% of all Australians living for at least five years after a diagnosis of cancer [1]. In addition to those who are cured of cancer, there is a growing population of survivors living with advanced disease as a result of improved treatment options and disease management. The result is a need to manage cancer as a chronic illness. While this change in conceptualisation is present in both health-related literature $[2,3]$ and in government policy and planning documents (4, $[4,5]$, it is yet to be translated into care system changes. People with advanced cancer continue to be primarily managed in the acute care setting, in part because of the increasing number of new treatment options available. In contrast, other well recognised chronic diseases, such as depression, hypertension and diabetes, are managed increasingly within the primary care setting [6-10].

Evidence-based models of chronic illness care exist and emphasise patient-centred care [11] and selfmanagement, with the aim of empowering both the patient and their caregivers to manage the illness. This is particularly important in the cancer setting where patients with advanced cancer have multiple needs and issues [12] and are primarily managed in an acute care setting but also receive care from health professionals in primary, community and home settings. Despite these complex care requirements, no specific model of care exists for advanced cancer and medical, psychosocial and practical support is mostly clinician-defined. This can result in poor care coordination and sub-optimal support for patients. In addition, communication with families [13] and between various health professionals such as primary care doctors may be inadequate.

In contrast, effective self-management of chronic conditions by patients and carers results in better communication with clinicians, improved self-reported health and lower distress, fewer hospitalisations and decreased health system costs [14]. To facilitate the selfmanagement aspects of cancer care, advanced practice nurses, also known by a variety of other titles including clinical nurse specialists and nurse care coordinators, are increasingly implemented to assist cancer patients and carers by providing education, medical, emotional and supportive care $[15,16]$. The aim of care coordination is to enhance the patient's experience during illness. In Australia, many dedicated cancer care coordinators are registered nurses, who practice within the context of a multidisciplinary team and are directly involved in care processes and plans to ensure all patient care requirements are arranged and delivered [17].

In addition, nurse-led telephone or out-reach calls to cancer patients have been trialled [18]. These out-reach calls offer an alternative to routine follow-up hospital visits, potentially reducing the burden on outpatient clinic services and negating the need for patients to travel [1823]. Furthermore, nurse-led telephone interventions provide psychological support, address informational needs [18,24], reduce emotional distress and enhance physical functioning for cancer patients [25]. These studies also suggest interactions by nurse specialists can promote patient self-management and reduce acute service utilisation.

Here, we present the outcomes of an exploratory participant observation study of patients with advanced cancer at an acute specialist cancer hospital in Australia. The overall objective was to understand the concerns and care requirements of people affected by advanced cancer and their health professionals. The aims of the study were:

1. to identify the care requirements and concerns of patients and their primary carers;

2. to examine the role of out-reach telephone calls as a component of care, and

3. to identify the nurse's role in care coordination for patients with advanced cancer.

This paper provides insight into the complexity of care required by and provided to patients with advanced cancer and those close to them and highlights the critical role of care coordination in meeting patient needs.

\section{Method}

An exploratory participant observation study was undertaken to establish the care coordination needs of patients with advanced breast or gastrointestinal (GI) cancer. Two specialist nurse clinician-researchers (CR) worked as care coordinators and were each responsible for the care of one of the two patient cohorts. The CRs recorded the type, frequency and reasons for interactions between the patients, their family and the treatment team and CRs. The data were augmented by individual interviews with the CRs conducted by an independent nurse researcher. The CRs were asked to discuss their role in the care of patients with advanced cancer.

The study was approved by the Human Ethics and Research Committee at the Peter MacCallum Cancer Centre, Melbourne, Australia.

\section{Recruitment}

Patients were eligible for the study if they had an advanced, incurable breast or GI cancer and were identified by their treating team as having multiple, complex issues and needs. Patients were informed about the study during an outpatient appointment and if they gave informed consent were introduced to the relevant CR. Data collection occurred over six and nine months respectively for the breast and GI patients, commencing in October, 2007. 


\section{Data collection}

Data were recorded on every interaction between the CRs and the patients, family members and/or carers and other health professionals both within the hospital and in the community using specifically designed data collection forms. Data on the physical, psychosocial and practical issues and concerns of both patients and carers were recorded, together with the actions performed by the CRs to facilitate a resolution of issues and concerns. The length of the interactions between the CR and patient/family member was also recorded.

Out-reach telephone calls to patients and carers were made by the CRs five to seven days prior to scheduled outpatient appointments to identify any issues that required interventions or investigations before attending the hospital. Calls were also made one to two days after commencement or change in treatment or when symptoms required close monitoring. The reasons for the out-reach call, length of call and outcome or required actions were all recorded on specifically designed forms by the CRs.

\section{Results \\ Patient Characteristics}

The patients with breast cancer $(n=12)$ ranged in age from 31 - 72 years (mean 51.5). The patients with GI cancers $(n=16)$ were slightly older (range $37-82$ years, mean 63.6$)$ and tended to have shorter survival times. Three women with breast cancer lived alone and did not identify a family member or support person while three patients with GI cancer lived alone but had an identified support person.

\section{Disease Characteristics}

A range of GI cancers were represented in this sample including neuroendocrine tumours, oesophageal, pancreatic, colorectal and gastric cancers. Most GI and one third of breast cancer patients were initially diagnosed with metastatic disease with the remainder diagnosed with early disease at the beginning that subsequently recurred. Nine patients died during the data collection period ( $n=8 \mathrm{GI}$, $n=1$ breast). The demographic and disease characteristics of the study patients are outlined in Table 1.

\section{Physical Symptoms}

A range of physical symptoms were self-reported by patients during data collection with pain, weakness and fatigue, and GI symptoms the most frequently discussed with the CR. (see Table 2)

\section{Frequency and mode of contact with patients}

A total of 501 contacts were made between the 28 patients, their carers and the CRs (see Table 3). One GI patient received all his contacts with the $\mathrm{CR}$ over the phone as he lived in rural Victoria and was too unwell to travel to Melbourne. There was no carer initiated contact for six patients with breast cancer and nine with GI cancer. The length of time spent on patient contacts from both groups ranged from 1 - 90 minutes (mean 12.6 minutes with breast patients and 11.5 minutes with GI patients). The recorded time spent with patients reflects the actual "direct contact time”; not including time spent by the CR following-up on issues and needs (indirect patient care).

\section{Planned Communication}

\section{Out-reach Phone Calls}

Twenty six out-reach calls were made to patients with breast cancer (range $0-5$ ) over six months while 99 calls (range $0-16$ ) were made to GI patients over nine months. One patient with breast cancer initiated constant contact with the CR and therefore did not receive an out-reach call and one patient from the GI group transferred his care to another hospital and so was not followed up.

When interviewed both CRs reported making more out-reach calls than originally planned (pre appointments and following a change in treatment or symptom profile) particularly to the GI patients during the quite rapid deterioration at the end of life. Despite the volume of outreach calls the CRs saw this as a time efficient and practical way of monitoring patients, identifying problems and intervening or coordinating support services.

Psychosocial needs were often identified during the out-reach calls. These needs required the CR to engage in therapeutic communication through active listening, eliciting and responding to emotional cues, and providing reassurance and support. Referrals to social work or psychology were also made when necessary. The CR for the patients with breast cancer said: "patients often said they could ask me things that they would not burden the doctor with".

\section{Calls or communication from patients and family}

The number of GI patient/carer initiated contacts with the CR ( $n=60)$ was higher than the breast cancer patient/carer initiated contacts $(n=40)$, however women 
Table 1: Patient Demographics

\begin{tabular}{|c|c|c|c|}
\hline & & $\begin{array}{l}\text { Patients with breast } \\
\text { cancer }(n=12)\end{array}$ & $\begin{array}{l}\text { Patients with } \mathrm{GI} \\
\text { cancers }(n=16)\end{array}$ \\
\hline \multirow[t]{2}{*}{ Gender } & Male & 0 & 11 \\
\hline & Female & 12 & 5 \\
\hline \multirow[t]{5}{*}{ Marital status } & Married & 5 & 12 \\
\hline & Single & 3 & 2 \\
\hline & Divorced & 2 & 0 \\
\hline & De Facto & 1 & 1 \\
\hline & Widowed & 1 & 1 \\
\hline \multirow[t]{5}{*}{ Employment Status } & Full Time & 3 & 1 \\
\hline & Part Time & 0 & 1 \\
\hline & Not working/Sick leave & 4 & 6 \\
\hline & Home Duties & 4 & 2 \\
\hline & Retired & 1 & 6 \\
\hline \multirow[t]{2}{*}{ Place of residence } & Metropolitan & 10 & 9 \\
\hline & Rural & 2 & 7 \\
\hline \multirow[t]{2}{*}{ Presence of disease } & Metastasis present at diagnosis & 4 & 14 \\
\hline & Early stage/local disease at diagnosis & 8 & 2 \\
\hline \multirow[t]{3}{*}{ Time to metastatic disease } & $<2$ years & 2 & 0 \\
\hline & $2-5$ years & 3 & 0 \\
\hline & $>5$ years & 3 & 2 \\
\hline \multirow[t]{6}{*}{ Site of Metastatic disease* } & Bone & 9 & 2 \\
\hline & Liver & 6 & 13 \\
\hline & Brain & 3 & 0 \\
\hline & Lung & 5 & 3 \\
\hline & Adrenal & 1 & 0 \\
\hline & Spleen & 0 & 1 \\
\hline \multirow{5}{*}{ Number of metastatic sites } & Nodal/omental/mesenteric & 0 & 1 \\
\hline & 1 & 7 & 12 \\
\hline & 2 & 0 & 4 \\
\hline & 3 & 3 & 0 \\
\hline & 4 & 2 & 0 \\
\hline \multirow[t]{7}{*}{ Treatment at recruitment ${ }^{\star \star}$} & Surgery & 2 & 0 \\
\hline & Chemotherapy & 4 & 10 \\
\hline & Biphosphonate therapy & 8 & 0 \\
\hline & Herceptin & 2 & 0 \\
\hline & Hormonal therapy & 7 & 0 \\
\hline & Radiotherapy & 1 & 2 \\
\hline & Palliative care & 0 & 6 \\
\hline
\end{tabular}

*Many patients had metastatic disease in multiple sites

**Many patients were receiving multimodal treatment at time of recruitment

with breast cancer used email more frequently $(n=16$ versus $n=3$ ). The patients with breast cancer tended to contact the CR when they needed advice or clarification about their care plan, but at the same time knew where and how to access support themselves. The CR said "I think these women have learnt to navigate their way around the system themselves and know where and how to access supports, they didn't need me for that". While the data shows GI patients did self initiate contact with the CR some tended to wait for the nurse to call them, even when they had a problem "When I asked why he hadn't phoned me when the pain got worse he said he didn't want to bother me and besides he knew I would call in the next day or so" (GI CR).

\section{Patient practical, informational and psychosocial concerns}

Patients reported 17 different practical and psychosocial concerns. The most common practical concern related to managing appointments which was raised by 20 of the patients on 47 occasions. Feeling anxious was the most common psychological concern, which was raised by 25 of the patients on 111 occasions. Other emotional concerns, such as fear, worry and ability to cope with the situation were raised on 24 occasions by nine patients from the GI group. The most common 
Table 2: Symptoms reported by patients

\begin{tabular}{|c|c|c|c|}
\hline Symptom & $\begin{array}{l}\text { Patients with breast cancer } \\
\qquad(n=12)\end{array}$ & $\begin{array}{l}\text { Patients with GI cancers } \\
\qquad(n=16)\end{array}$ & $\begin{array}{l}\text { No. of times } \\
\text { reported }\end{array}$ \\
\hline Pain & 11 & 12 & 117 \\
\hline Weakness/Fatigue & 7 & 14 & 96 \\
\hline GIT Symptoms $^{\underline{1}}$ & 8 & 14 & 120 \\
\hline $\begin{array}{l}\text { Respiratory Symptoms } \\
\text { (dyspnoea, cough) }\end{array}$ & 3 & 7 & 34 \\
\hline $\begin{array}{l}\text { Cardiac Symptoms } \\
\text { (palpitations, swollen limbs) }\end{array}$ & 4 & 5 & 26 \\
\hline $\begin{array}{l}\text { Neurological Symptoms } \\
\text { (dizziness/drowsiness/confusion) }\end{array}$ & 4 & 7 & 34 \\
\hline Restlessness/panic attacks & 1 & 1 & 6 \\
\hline Mouth/teeth problems & 3 & 3 & 10 \\
\hline Rash/skin problems & 2 & 3 & 12 \\
\hline Insomnia/sleep disturbance & 5 & 3 & 13 \\
\hline Miscellaneous ${ }^{2}$ & 5 & 9 & 63 \\
\hline
\end{tabular}

${ }^{1}$ GIT symptoms include constipation, diarrhoea, abdominal symptoms, nausea and vomiting, dysphagia, anorexia/weight loss, jaundice

${ }^{2}$ Miscellaneous symptoms include alopecia, fever/sweating, shoulder problems, potential infection, urinary symptoms, hormonal symptoms, decreased mobility and bleeding/haemoserous ooze.

\section{Table 3: Frequency and mode of contact with patients}

\begin{tabular}{lcc}
\hline & $\begin{array}{c}\text { Patients with } \\
\text { breast cancer } \\
(\mathrm{n}=12)\end{array}$ & $\begin{array}{c}\text { Patients with GI } \\
\text { cancers } \\
(\mathrm{n}=16)\end{array}$ \\
$\begin{array}{l}186 \\
\text { Total number of contacts }\end{array}$ & $16(3-26)$ & $20(2-42)$ \\
Mean per patient (range) & 72 & 88 \\
Face-to-face & 58 & 160 \\
Telephone to patient/carer* & 21 & 25 \\
Telephone from patient & 3 & 32 \\
Telephone from carer & 16 & 0 \\
Email to patient/carer & 16 & 3 \\
Email from patient/carer & $27^{\wedge}$ & $44^{\wedge \wedge}$ \\
Number of days with multiple & & \\
contacts with the same patient(s) & \\
$*$ Includes planned out-reach calls and unplanned or unscheduled calls \\
$\wedge$ Range of contacts with one breast patient in one day 2-5 \\
$\wedge$ Range of contacts with one GI patient in one day 2-4
\end{tabular}

informational concern was a desire for clarification about the treatment options which had been discussed with the oncologist, which was raised by 19 of the patients on 80 occasions. See Table 4 for detail.

\section{Carer practical and psychosocial concerns}

Six different practical issues and five psychosocial concerns were raised by patients' carers (see Table 5). Carers were most commonly concerned about their ability to deal with patient symptoms and their own anxiety. Differences in the concerns raised by the two groups of carers were noted and possibly related to differences in the prognosis of the breast and GI patients. Carers of patients with GI cancers expressed concerns about decisions relating to the need for hospitalisation, their ability to provide all support required, dealing with finances and arranging transport. These issues were not raised by the carers of the women with breast cancer.

\section{Clinician researcher actions}

Most interactions with the patients and/or their carers required subsequent action by the CR. Seventeen different types of actions were performed by the CR with the number of actions carried out across the study totalling 1064. Provision of supportive medication and symptom management advice, liaison with hospital staff, managing appointments and checking on how patients and carers were managing at home were the most frequent actions performed. All actions were required by GI patients while five actions were not required by the 
Table 4: Patient practical and psychosocial concerns

\begin{tabular}{|c|c|c|c|c|}
\hline Issues & & $\begin{array}{l}\text { No. of Breast } \\
\text { Patients } \\
\text { (from } n=12 \text { ) }\end{array}$ & $\begin{array}{l}\text { No. of GI Patients } \\
\text { (from } n=16 \text { ) }\end{array}$ & $\begin{array}{l}\text { No. of } \\
\text { times } \\
\text { reported }\end{array}$ \\
\hline \multirow[t]{9}{*}{ Practical } & $\begin{array}{l}\text { Clarification and management of } \\
\text { appointments }\end{array}$ & 8 & 12 & 47 \\
\hline & Dealing with medications & 4 & 6 & 28 \\
\hline & $\begin{array}{l}\text { Obtaining results of blood tests and } \\
\text { investigations }\end{array}$ & 2 & 5 & 25 \\
\hline & Managing financial concerns & 4 & 2 & 20 \\
\hline & Managing at home & 2 & 6 & 11 \\
\hline & Caring for venous access devices & 1 & 4 & 8 \\
\hline & $\begin{array}{l}\text { Managing complimentary and } \\
\text { alternative therapies in conjunction with } \\
\text { standard treatments }\end{array}$ & 1 & 2 & 7 \\
\hline & Arranging accommodation & 0 & 3 & 4 \\
\hline & Managing co-morbidities & 1 & 0 & 2 \\
\hline \multirow[t]{8}{*}{ Psychosocial } & Feeling anxious & 12 & 13 & 111 \\
\hline & $\begin{array}{l}\text { Clarification of treatment options as } \\
\text { discussed with specialists }\end{array}$ & 9 & 10 & 80 \\
\hline & $\begin{array}{l}\text { Emotional issues such as how to cope, } \\
\text { fear and general worry }\end{array}$ & 0 & 9 & 24 \\
\hline & Concerns about family carers & 5 & 3 & 17 \\
\hline & Desire to know prognosis & 4 & 6 & 13 \\
\hline & $\begin{array}{l}\text { Concerns regarding quality of care being } \\
\text { provided }\end{array}$ & 3 & 3 & 9 \\
\hline & Dealing with uncertainty & 0 & 3 & 7 \\
\hline & $\begin{array}{l}\text { Meaning of palliative care and } \\
\text { implications of palliative care involvement }\end{array}$ & 1 & 2 & 4 \\
\hline
\end{tabular}

Table 5: Carer practical and psychosocial concerns

\begin{tabular}{|c|c|c|c|c|}
\hline Issues & & $\begin{array}{l}\text { No. of Breast } \\
\text { Carers } \\
\text { (from } n=9 \text { ) }\end{array}$ & $\begin{array}{c}\text { No. of GI } \\
\text { Carers } \\
\text { (from } n=16 \text { ) }\end{array}$ & $\begin{array}{l}\text { No. of times } \\
\text { reported }\end{array}$ \\
\hline \multirow[t]{6}{*}{ Practical } & Managing patient symptoms & 2 & 9 & 52 \\
\hline & Obtaining results & 4 & 6 & 30 \\
\hline & Managing appointments & 2 & 6 & 15 \\
\hline & Ability to provide support & 0 & 2 & 3 \\
\hline & Arranging transport & 0 & 2 & 2 \\
\hline & Managing financial concerns & 0 & 1 & 1 \\
\hline \multirow[t]{5}{*}{ Psychosocial } & Dealing with own anxiety & 5 & 9 & 62 \\
\hline & Having end of life discussions with the patient & 1 & 5 & 14 \\
\hline & $\begin{array}{l}\text { Meaning of palliative care and implications of } \\
\text { palliative care involvement }\end{array}$ & 1 & 4 & 11 \\
\hline & $\begin{array}{l}\text { Discussing whether or not the patient required a } \\
\text { hospital admission }\end{array}$ & 0 & 3 & 6 \\
\hline & Psychological health of the patient & 0 & 1 & 5 \\
\hline
\end{tabular}

patients with breast cancer (Table 6). A number of actions, such as arranging transport, rearranging or making appointments, faxing referrals, booking procedures (e.g. ascetic taps and blood transfusions) were administrative in nature and did not require nursing expertise. On average each patient required 38 actions with a range of 2-42 across the total period they were enrolled in the study.

Further detail about the CR's actions was identified during the interviews. Both CRs described their role in broad terms as including problem solving, acting as a resource person and point of contact within the hospital. They believed their existence and actions benefited patients and their carers by facilitating the journey through the health system. One said "I think the patients liked having someone within the hospital who 'knew their story' and who was interested in them as individuals as well." 
Table 6: Clinician researcher actions.

\begin{tabular}{|c|c|c|}
\hline \multirow[t]{2}{*}{ Actions } & \multicolumn{2}{|c|}{ Frequency of action } \\
\hline & $\begin{array}{l}\text { Breast Patient } \\
\quad(n=12)\end{array}$ & $\begin{array}{l}\text { GI Patient } \\
(\mathrm{n}=16)\end{array}$ \\
\hline $\begin{array}{l}\text { Provision of supportive communication or reassurance to patients or } \\
\text { family members }\end{array}$ & 120 & 130 \\
\hline $\begin{array}{l}\text { Arrange another time to check on patient and/or carer (includes hospital } \\
\text { appointments and outreach calls) }\end{array}$ & 62 & 160 \\
\hline Liaise with clinicians and hospital staff & 77 & 110 \\
\hline $\begin{array}{l}\text { Providing advice on managing symptoms, nutritional requirements, } \\
\text { medications }\end{array}$ & 50 & 63 \\
\hline Making, changing, cancelling and clarifying appointments* & 31 & 48 \\
\hline $\begin{array}{l}\text { Seek clarification of issues discussed with clinicians during previous } \\
\text { appointments }\end{array}$ & 22 & 17 \\
\hline Booking, organising and copying investigations (eg; blood tests)* & 9 & 19 \\
\hline Making a referral to an allied health professional at the hospital & 16 & 9 \\
\hline Organise a hospital admission (Inpatient and day patient stay) & 4 & 14 \\
\hline Advise to go to GP & 3 & 11 \\
\hline Making a referral to a community palliative care service & 0 & 12 \\
\hline Liaise with GPs about a change in condition or treatment & 6 & 6 \\
\hline Organise transport for a future hospital appointment e.g. ambulance* & 0 & 8 \\
\hline Discussing the benefits and draw backs of venous access devices & 0 & 5 \\
\hline $\begin{array}{l}\text { Making a referral to the hospital based palliative care consultancy } \\
\text { service }\end{array}$ & 0 & 4 \\
\hline Making a referral to a generalist community nursing service & 0 & 3 \\
\hline Miscellaneous^^$\wedge^{\wedge}$ & 27 & 19 \\
\hline
\end{tabular}

$\wedge$ Miscellaneous: organising scripts, accommodation and wound dressings, sending out written resources

*Actions that do not require nursing input

The care coordination role performed by the CR also benefited the medical staff and assisted in the provision of quality cancer care as illustrated by one CR who said " $I$ don't know how he [the medical oncologist] followed up blood results, arranged treatment times, transport and all the extra support services before me and this project because he certainly doesn't do all that now."

\section{Discussion}

This paper addresses three aims: to identify the care requirements and concerns of patients with advanced breast and GI cancer as well as those of their primary carer, to examine the role of out-reach telephone calls made by the $\mathrm{CR}$, and to understand the role of the nurse in the care coordination of patients with advanced cancer. The results highlight the value of having a nurse in a coordination role who is able to identify and address the 'support gaps' that exist for patients being treated for advanced cancer in a specialist centre.

The role of the CR in this study was established as a specialist or advanced practice role. Such roles are increasingly promoted as appropriate and necessary for the provision of specialised cancer care [26,27]. Advanced roles have been successful for women with gynaecological cancers recovering from surgery and undergoing chemotherapy as measured by symptom and support outcomes, dissemination of information, and coordination of referrals and resources [28]. They have also been successful in radiation oncology multidisciplinary teams as evidenced by the provision of direct patient care, involvement in specialized procedures, and conducting initial and/or follow-up visits [29]. A structured review of the literature on specialist nursing roles in chronic disease management such as diabetes, coronary heart disease and chronic obstructive respiratory disease also concluded that nurses in such roles impact positively on care coordination, quality of life and functionality and self care [30].(

The existing nurse co-ordinator (NC) roles at the study hospital, upon which the CR role was modelled, traditionally focus on patients newly diagnosed with cancer and on those with early stage disease receiving first line treatment. This focus evolved because many of these roles were funded by surgical and radiotherapy services resulting in the development of close working relationships between the nurse and surgeon/radiation oncologist. In contrast, patients with persistent, recurrent or metastatic disease remain somewhat invisible within the health care system despite the substantial growth in numbers [10]. This seems to be a problem in both the US [10] and Australia where it is nearly impossible to identify the number of people living with advanced cancer as a central database containing such detail does not exist.

In the study hospital patients with advanced cancer are only brought to the attention of the NC when problems or issues are identified by other team members. This can be 
partially explained as a result of the absence of standard and routine work processes for linking patients with advanced disease to a designated NC. Yet research by Aranda and colleagues [31,32]found that women with advanced breast cancer, who had high initial needs and then received interventions by breast care nurses had reduced emotional and psychological needs over time suggesting routine identification of such patients is required and would be beneficial.

The data in this study demonstrated the large number and range of practical and psychosocial issues experienced by both cohorts and the subsequent actions carried out by the CRs. The issues were similar for both groups with almost all patients reporting at least one psychosocial concern which reflects evidence from earlier studies suggesting that many patients with advanced cancer experience psychosocial concerns [33,34]. The high volume of issues reported may reflect the relatively poor performance status of the GI cohort in particular (half of the sample died within the nine months of data collection) and the well developed breast care services which promote a culture of voicing needs and asking for support.

One of the highest volume actions carried out by the CR was the provision of supportive communication and reassurance to both the patient and family member. Most often this meant clarifying results of investigations and the risks and benefits of different treatment options as well as the normalisation of fears and concerns. Such therapeutic interactions need to be tailored to the specific issues faced by people affected by advanced cancer rather than mimicking interactions routinely undertaken with people dealing with a potentially curable disease [35].

The high proportion of patients reporting pain (92\% of breast versus $75 \%$ of GI patients) and fatigue and weakness (58\% versus 88\%) reflects findings from other studies [36]. Gastrointestinal symptoms including diarrhoea, constipation, nausea and vomiting were also problematic for the majority of the participants (67\% of breast versus $88 \%$ of GI patients). This symptom profile, when considered in conjunction with the multitude of psychosocial issues reported illustrates the complex care requirements of patients with advanced cancer and supports the argument for having a specialist nurse available to these patients. Nurses in care co-ordination roles who are attuned to the complex needs of patients and family members are well positioned to identify gaps in care delivery and then develop appropriate interventions [10]. With the growing number of patients living with advanced cancer for considerable periods of time, interventions must incorporate self care where feasible and support for family or friend caregivers when necessary [10].

In addition to care co-ordination provided by specialist nurses, patient care was also enhanced by the structured use of out-reach calls as they were a feasible and effective way to monitor the patients and to reduce the need for the patients to travel to the acute hospital. Other studies of telephone interventions, both in cancer care and in chronic illness care, have shown mixed results in terms of helping patients manage their illness at home. Patients with heart disease were found to require fewer hospitalisations and showed greater adherence to treatment recommendations following a telephone intervention [37-39]. While in a cohort of patients with poorly controlled type 1 diabetes, hospital admissions were not reduced and psychological functioning did not improve but patients rated the calls as helpful [40]. Within a cancer setting Allard [25] showed that a telephone intervention following day surgery for 117 patients with breast cancer reduced emotional distress and enhanced physical functioning and Anastasia [41] describes the benefits of nurse-led telephone management of chemotherapy side-effects when the nurse is highly skilled and familiar with treatment related side-effects. In this study the out-reach calls were deemed important when considered in light of the patients' reluctance to ask doctors all their questions during clinic appointments. Although a degree of caution must be exercised if relying on out-reach calls as a two way means of monitoring patients at home given that some patients chose not to initiate a call when a problem occurred because they knew a call from the CR was scheduled later in the week. Despite this caution this study supports the conclusion reached by Cox and Wilson [42] that nurse-led follow up by telephone was an acceptable, efficient and appropriate means of maintaining contact with a cancer population and provides vital support to vulnerable patients. However, formal evaluation of the effectiveness, long term sustainably and funding options of such out-reach calls within an advanced cancer setting is now required.

In summary, this study has provided significant insight into the range of concerns and issues and the associated complexity of care required by patients with advanced cancer and their carers attending an acute specialist cancer hospital. The issues, needs and concerns experienced by patients and their carers illustrate the diversity of care requirements that require attention by health professionals in order to make the model of care more person-centered. As new biological targeted treatments for cancer begin to fulfil the hope of turning advanced cancer into a chronic disease, there is a clear advantage in having cancer nurses with advanced skills who can effectively assist in the care coordination and management of patients and their carers living with advanced cancer.

\section{Acknowledgements}

The authors would like to thank to all the patients, their family members and treating clinicians who were so willing to talk to us about their experiences. The authors also wish to acknowledge and give special thanks to Victoria Foletta for the early work she did on this manuscript. Thanks also to Jackie Kearney from the Cancer and Palliative Care Unit, Victorian Department of Health for the financial support that allowed us to extend the literature review beyond the scope of this study. Thanks must also be extended to members of the project 
steering committee who provided guidance and support to the study nurse coordinators: Dr Linda Mileshkin, Ms Tina Griffiths, Dr Michael Michael, Ms Meg Rogers, $\mathrm{Mr}$ Michael Collins, Ms Helen McLennan, Mrs Helen Anstis, Dr Kate Robbins-Browne, Mr Stephen Thomas, Dr Frank Vetere and Dr Lemai Ngyen.

\section{References}

[1] Australian Institute of Health and Welfare. Australia's Health 2008. Canberra 2008. Report No.: Cat. no. Aus 99.

[2] Beyer DA. (1995) Cancer is a chronic disease. Nurse Practitioner Forum. Dec;6(4):201-6.

[3] Sharma DC. (2006). WHO groups cancer together with chronic diseases. Lancet Oncology Mar;7(3):200.

[4] Victorian Government Department of Human Services. Victoria's Cancer Action Plan 2008-2011. Melbourne 2008.

[5] National Health and Hospitals Reform Commission. A Healthier Future for all Australians. Final report June 2009. Canberra.

[6] Wagner E, Grothaus LC, Sandhu N, Galvin SA, McGregor M, Artz K, et al. (2001). Chronic care clinics for diabetes in primary care. A system wide randomized trial. Diabetes Care. 25(4):695-700.

[7] Bodenheimer T, Wagner E, Grumbach K. (2002). Improving primary care for patients with chronic illness. Journal of American Medical Association. 288(14):1775-9. [8] Zwar N, Harris M, Griffiths R, Roland M, Dennis S, Powell Davies G, et al. (2006). A systematic review of chronic disease management. Sydney: Research Centre for Primary Health Care and Equity, University of New South Wales.

[9] Harris MF, Zwar N. (2007). Care of patients with chronic disease: The challenge for general practice. Medical Journal of Australia. 187(2):104-7.

[10] Haylock PJ. (2010) Advanced cancer: Emergence of a new survivor population. Seminars in Oncology Nursing. 26(3):144-50.

[11] Wagner EH, Bennett SM, Austin BT, Greene SM, Schaefer JK, Vonkorff M. (2005). Finding common ground: patient-centeredness and evidence-based chronic illness care. Journal of Alternative and Complementary Medicine. 11 Suppl 1:S7-15.

[12] Fitch MI. (2005). Needs of patients living with advanced disease. Canadian Oncology Nursing Journal. 15(4):230-42.

[13] Davis S, Kristjanson LJ, Blight J. (2003). Communicating with families of patients in an acute hospital with advanced cancer: problems and strategies identified by nurses. Cancer Nursing. Oct;26(5):337-45.

[14] Barlow J, Wright C, Sheasby J, Turner A, Hainsworth J. (2002). Self-management approaches for people with chronic conditions: a review. Patient Education and Counseling. Oct -Nov;48(2):177-87.
[15] Cunningham RS. (2004). Advanced practice nursing outcomes: a review of selected empirical literature. Oncology Nursing Forum. Mar-Apr;31(2):219-32.

[16] Murphy-Ende K. (2002). Advanced practice nursing: reflections on the past, issues for the future. Oncology Nursing Forum. Jan-Feb;29(1):106-12.

[17] Yates P. (2004). Cancer care coordinators: Realising the potential for improving the patient journey. Cancer Forum. 28(3):128-31.

[18] Cox A, Bull E, Cockle-Hearne J, Knibb W, Potter C, Faithfull S. (2008). Nurse led telephone follow up in ovarian cancer: a psychosocial perspective. European Journal of Oncology Nursing. Dec;12(5):412-7.

[19] Booker J, Eardley A, Cowan R, Logue J, Wylie J, Caress AL. (2004). Telephone first post-intervention follow-up for men who have had radical radiotherapy to the prostate: evaluation of a novel service delivery approach. European Journal of Oncology Nursing. Dec;8(4):325-33.

[20] Faithfull S, Corner J, Meyer L, Huddart R, Dearnaley D. (2001). Evaluation of nurse-led follow up for patients undergoing pelvic radiotherapy. British Journal of Cancer. Dec 14;85(12):1853-64.

[21] Lewis R, Neal RD, Williams NH, France B, Wilkinson C, Hendry M, et al. (2009). Nurse-led vs. conventional physician-led follow-up for patients with cancer: systematic review. Journal of Advanced Nursing. Apr;65(4):706-23.

[22] Sardell S, Sharpe G, Ashley S, Guerrero D, Brada M. (2000). Evaluation of a nurse-led telephone clinic in the follow-up of patients with malignant glioma. Clinical oncology (Royal College of Radiologists (Great Britain)). 12(1):36-41.

[23] Shaida N, Jones C, Ravindranath N, Das T, Wilmott $\mathrm{K}$, Jones A, et al. (2007). Patient satisfaction with nurseled telephone consultation for the follow-up of patients with prostate cancer. Prostate Cancer and Prostatic Diseases. 10(4):369-73.

[24] Beaver K, Twomey M, Witham G, Foy S, Luker KA. (2006). Meeting the information needs of women with breast cancer: piloting a nurse-led intervention. European Journal of Oncology Nursing. Dec;10(5):378-90.

[25] Allard NC. (2007). Day surgery for breast cancer: effects of a psychoeducational telephone intervention on functional status and emotional distress. Oncology Nursing Forum. Jan;34(1):133-41.

[26] Eicher MRE, Marquard S, Aebi S. (2003). A nurse is a nurse? A systematic review of the effectiveness of specialised nursing in breast cancer. European Journal of Cancer. 42:3117-26.

[27] Yates P. (2007). Achieving coordinated cancer care: Report on the clinical oncological society of Australia care coordination workshop. Cancer Forum. 31(3):169-72.

[28] McCorkle R, Dowd M, Ercolano E, Schulman-Green D, Williams AL, Siefert ML, et al. (2009). Effects of a nursing intervention on quality of life outcomes in postsurgical women with gynecological cancers. Psychooncology. Jan;18(1):62-70. 
[29] Carper E, Haas M. (2006). Advanced practice nursing in radiation oncology. Seminars in Oncology Nursing. Nov;22(4):203-11.

[30] Sutherland D, Hayter M. (2009). Structured review: evaluating the effectiveness of nurse case managers in improving health outcomes in three major chronic diseases. Journal of Clinical Nursing. 18:2978-92.

[31] Aranda S, Schofield P, Weih L, Yates P, Milne D, Faulkner R, et al. (2005). Mapping the quality of life and unmet needs of urban women with metastatic breast cancer. European Journal of Cancer Care (Engl). Jul;14(3):211-22.

[32] Aranda S, Schofield P, Weih L, Milne D, Yates P, Faulkner R. (2006). Meeting the support and information needs of women with advanced breast cancer: a randomised controlled trial. British Journal of Cancer. 95:667-73.

[33] Given BA, Given CW, Kozachik S. (2001). Family support in advanced cancer. CA: Cancer Journal for Clinicians. Jul-Aug;51(4):213-31.

[34] Vachon ML, Kristjanson L, Higginson I. (1995). Psychosocial issues in palliative care: the patient, the family, and the process and outcome of care. Journal of Pain and Symptom Management. Feb;10(2):142-50.

[35] Marcusen C. (2010). Information and communication needs of individuals living with advanced cancer. Seminars in Oncology Nursing. 26(3):151-6.

[36] Wong RK, Franssen E, Szumacher E, Connolly R,
Evans M, Page B, et al. (2002). What do patients living with advanced cancer and their carers want to know? A needs assessment. Supportive Care in Cancer. 10:408-15.

[37] Jerant AF, Azari R, Martinez C, Nesbitt TS. (2003). A randomized trial of telenursing to reduce hospitalization for heart failure: patient-centered outcomes and nursing indicators. Home Health Care Services Quarterly 22(1):120.

[38] Wheeler EC, Waterhouse JK. (2006). Telephone interventions by nursing students: improving outcomes for heart failure patients in the community. Journal of Community Health Nursing. Fall; 23(3):137-46.

[39] Shearer NB, Cisar N, Greenberg EA. (2007). A telephone-delivered empowerment intervention with patients diagnosed with heart failure. Heart Lung. MayJun;36(3):159-69.

[40] Nunn E, King B, Smart C, Anderson D. (2006). A randomised controlled trial of telephone calls to young patients with poorly controlled type 1 diabetes. Pediatric Diabetes. 7(5):254-9.

[41] Anastasia P. (2002). Telephone triage and chemotherapy symptom management in the ambulatory care setting. Oncology Supportive Care Quarterly. 1:4055.

[42] Cox K, Wilson E. (2003). Follow up for people with cancer: nurse-led services and telephone interventions. Journal of Advanced Nursing. 43(1):51-61. 